\title{
Fixed Point Results of Locally Contractive Mappings in Ordered Quasi-Partial Metric Spaces
}

\author{
Abdullah Shoaib, ${ }^{1}$ Muhammad Arshad, ${ }^{1}$ and Jamshaid Ahmad ${ }^{2}$ \\ ${ }^{1}$ Department of Mathematics, International Islamic University, H-10, Islamabad 44000, Pakistan \\ ${ }^{2}$ Department of Mathematics, COMSATS Institute of Information Technology, Chak Shahzad, Islamabad 44000, Pakistan
}

Correspondence should be addressed to Muhammad Arshad; marshad_zia@yahoo.com

Received 30 April 2013; Accepted 18 June 2013

Academic Editors: A. Bekir, A. Ibeas, and A. M. Peralta

Copyright (C) 2013 Abdullah Shoaib et al. This is an open access article distributed under the Creative Commons Attribution License, which permits unrestricted use, distribution, and reproduction in any medium, provided the original work is properly cited.

Fixed point results for a self-map satisfying locally contractive conditions on a closed ball in an ordered 0-complete quasi-partial metric space have been established. Instead of monotone mapping, the notion of dominated mappings is applied. We have used weaker metric, weaker contractive conditions, and weaker restrictions to obtain unique fixed points. An example is given which shows that how this result can be used when the corresponding results cannot. Our results generalize, extend, and improve several well-known conventional results.

\section{Introduction and Preliminaries}

Fixed points results of mappings satisfying certain contractive conditions on the entire domain have been at the centre of vigorous research activity, (see [1-3]) and it has a wide range of applications in different areas such as nonlinear and adaptive control systems, parameterize estimation problems, fractal image decoding, computing magnetostatic fields in a nonlinear medium, and convergence of recurrent networks (see [4-6]).

Recently, many results appeared related to fixed point theorem in complete metric spaces endowed with a partial ordering in the literature. Ran and Reurings [7] proved an analogue of Banach's fixed point theorem in metric space endowed with a partial order and gave applications to matrix equations. In this way, they weakened the usual contraction condition. Subsequently, Nieto and Rodríguez-López [8] extended the result in [7] for nondecreasing mappings and applied it to obtain a unique solution for a 1st-order ordinary differential equation with periodic boundary conditions. Thereafter, many works related to fixed point problems have also been considered in partially ordered metric spaces (see [7-11]).

On the other hand notion of a partial metric space was introduced by Matthews in [12]. In partial metric spaces, the distance of a point from itself may not be zero. Partial metric spaces have applications in theoretical computer science (see [13]). Altun and Erduran [14] and Paesano and Vetro [15] used the idea of partial metric space and partial order and gave some fixed point theorems for contractive condition on ordered partial metric spaces. Recently, Karapinar et al. [16] introduced the concept of quasi-partial metric space. Romaguera [17] has given the idea of 0-complete partial metric space. Nashine et al. [18] used this concept and proved some classical results.

From the application point of view the situation is not yet completely satisfactory because it frequently happens that a mapping $T$ is a contraction not on the entire space $X$ but merely on a subset $Y$ of $X$. However, if $Y$ is closed and a sequence $\left\{x_{n}\right\}$ in $X$ converges to some $x$ in $X$, then by imposing a subtle restriction on the choice of $x_{0}$, one may force the sequence to stay eventually in $Y$. In this case, one can establish the existence of a fixed point of T. Arshad et al. [19] proved a significant result concerning the existence of fixed points of a mapping satisfying a contractive conditions on closed ball in a complete dislocated metric space. Other results on closed ball can be seen in $[20,21]$. In this paper we have obtained fixed point theorems for dominated self-mappings in a 0 complete ordered quasi-partial metric space on closed ball under several contractive conditions to generalize, extend 
and improve some classical fixed point results. We have used weaker contractive condition and weaker restrictions to obtain unique fixed point. Our results do not exist even yet in metric spaces. An example shows how this result can be used when the corresponding results cannot.

Consistent with $[16,22,23]$ the following definitions and results will be needed in the sequel.

Definition 1 (see [16]). A quasi-partial metric is a function $q: X \times X \rightarrow R^{+}$satisfying the following:

(i) if $0 \leq q(x, x)=q(x, y)=q(y, y)$, then $x=y$ (equality);

(ii) $q(x, x) \leq q(y, x)$ (small self-distances);

(iii) $q(x, x) \leq q(x, y)$ (small self-distances);

(iv) $q(x, z)+q(y, y) \leq q(x, y)+q(y, z)$ (triangle inequality), for all $x, y, z \in X$.

The pair $(X, q)$ is called a quasi-partial metric space.

Note that if $q(x, y)=q(y, x)$ for all $x, y \in X$, then $(X, q)$ becomes a partial metric space $(X, p)$. Moreover if $q(x, x)=0$ for all $x \in X$, then $(X, q)$ and $(X, p)$ become a quasimetric space and a metric space, respectively. Also $p_{q}(x, y)=(1 / 2)[q(x, y)+q(y, x)], x, y \in X$ is a partial metric on $X$. The function $d_{p_{q}}: X \times X \rightarrow R^{+}$defined by $d_{p_{q}}(x, y)=$ $q(x, y)+q(y, x)-q(x, x)-q(y, y)$ is a (usual) metric on $X$. The ball $\overline{B(x, \varepsilon)}$, where $\overline{B(x, \varepsilon)}=\{y \in X: q(x, y) \leq \varepsilon+q(x, x)\}$, is a closed ball in quasi-partial metric space, for some $x \in X$ and $\varepsilon>0$.

Definition 2 (see $[16])$. Let $(X, q)$ be a quasi-partial metric. Then, we have the following;

(a) A sequence $\left\{x_{n}\right\}$ in $(X, q)$ converges to a point $x \in X$ if and only if $\lim _{n \rightarrow \infty} q\left(x, x_{n}\right)=\lim _{n \rightarrow \infty} q\left(x_{n}, x\right)=$ $q(x, x)$.

(b) A sequence $\left\{x_{n}\right\}$ in $(X, q)$ is called a Cauchy sequence if the limits $\lim _{n, m \rightarrow \infty} q\left(x_{n}, x_{m}\right)$ and $\lim _{n, m \rightarrow \infty} q\left(x_{m}, x_{n}\right)$ exist (and are finite).

(c) The space $(X, q)$ is said to be complete if every Cauchy sequence $\left\{x_{n}\right\}$ in $(X, q)$ converges to a point $x \in X$ such that $(x, x)=\lim _{n, m \rightarrow \infty} q\left(x_{n}, x_{m}\right)=$ $\lim _{n, m \rightarrow \infty} q\left(x_{m}, x_{n}\right)$.

Lemma 3 (see $[16])$. Let $(X, q)$ be a quasi-partial metric space, let $\left(X, p_{q}\right)$ be the corresponding partial metric space, and let $\left(X, d_{p_{q}}\right)$ be the corresponding metric space. These statements are equivalent. (i) The sequence $\left\{x_{n}\right\}$ is Cauchy in $(X, q)$. (ii) The sequence $\left\{x_{n}\right\}$ is Cauchy in $\left(X, p_{q}\right)$. (iii) The sequence $\left\{x_{n}\right\}$ is Cauchy in $\left(X, d_{p_{q}}\right)$. These statements are also equivalent. (i) $(X, q)$ is complete. (ii) $\left(X, p_{q}\right)$ is complete. (iii) $\left(X, d_{p_{q}}\right)$ is complete.

Definition 4. Let $(X, \preceq)$ be a partial ordered set. Then $x, y \in X$ are called comparable if $x \preceq y$ or $y \preceq x$ holds.

Definition 5 (see $[22])$. Let $(X, \preceq)$ be a partially ordered set. A self-mapping $f$ on $X$ is called dominated if $f x \preceq x$ for each $x$ in $X$.
Example 6 (see [22]). Let $X=[0,1]$ be endowed with the usual ordering and $f: X \rightarrow X$ defined by $f x=x^{n}$ for some $n \in \mathbb{N}$. Since $f x=x^{n} \leq x$ for all $x \in X$, therefore $f$ is a dominated map.

Theorem 7 (see [23]). Let $(X, d)$ be a complete metric space, $S: X \rightarrow X$ a mapping, $r>0$, and $x_{0}$ an arbitrary point in $X$. Suppose there exists $k \in[0,1)$ with

$$
d(S x, S y) \leq k d(x, y), \quad \text { for all } x, y \in Y=\overline{B\left(x_{0}, r\right)}
$$

and $d\left(x_{0}, S x_{0}\right)<(1-k) r$. Then there exists a unique point $x^{*}$ in $\overline{B\left(x_{0}, r\right)}$ such that $x^{*}=S x^{*}$.

\section{Fixed Points of Dominated Mapping}

In this section we introduce the notion of a 0 -complete quasipartial metric spaces. We also prove some results in these spaces.

Definition 8. Let $(X, q)$ be a quasi-partial metric space.

(a) A sequence $\left\{x_{n}\right\}$ in $(X, q)$ is called 0-Cauchy if $\lim _{n, m \rightarrow \infty} q\left(x_{n}, x_{m}\right)=0$ or $\lim _{n, m \rightarrow \infty} q\left(x_{m}, x_{n}\right)=0$.

(b) The space $(X, q)$ is called 0 -complete if every 0 Cauchy sequence in $X$ converges to a point $x \in X$ such that $q(x, x)=0$.

It is easy to see that every 0 -Cauchy sequence in $(X, q)$ is Cauchy in $\left(X, d_{p_{q}}\right)$ and if $(X, q)$ is complete, then it is 0 complete but the converse assertions do not hold. For example, the space $X=[0,+\infty) \cap Q$ with $q(x, y)=|x-y|+|x|$ is a 0 -complete quasi-partial metric space but it is not complete (since $d_{p_{q}}(x, y)=2|x-y|$ and $\left(X, d_{p_{q}}\right)$ is not complete).

Moreover, if $(X, d)$ is complete quasimetric space which is also quasi-partial, then it is 0 -complete, quasi-partial metric space.

Definition 9. Let $X$ be a nonempty set. Then $(X, \preceq, q)$ is called an ordered quasi-partial metric space if (i) $q$ is a quasi-partial metric on $X$ and (ii) $\preceq$ is a partial order on $X$.

Theorem 10. Let $(X, \preceq, q)$ be a 0 -complete ordered quasipartial metric space, $S: X \rightarrow X$ a dominated map, and $x_{0}$ an arbitrary point in $X$. Suppose that there exists $k \in[0,1)$ such that

$$
\begin{aligned}
& q(S x, S y) \leq k q(x, y) \\
& \quad \text { for all comparable elements } x, y \text { in } \overline{B\left(x_{0}, r\right)} .
\end{aligned}
$$

And

$$
q\left(x_{0}, S x_{0}\right) \leq(1-k)\left[r+q\left(x_{0}, x_{0}\right)\right] \text {. }
$$

If, for a nonincreasing sequence $\left\{x_{n}\right\}$ in $\overline{B\left(x_{0}, r\right)},\left\{x_{n}\right\} \rightarrow u$ implies that $u \preceq x_{n}$, then there exists a point $x^{*}$ in $\overline{B\left(x_{0}, r\right)}$ such that $x^{*}=S x^{*}$ and $q\left(x^{*}, x^{*}\right)=0$. Moreover, $x^{*}$ is unique, if for every pair of elements $x, y$ in $X$ there exists a point $z \in X$ such that $z \preceq x$ and $z \preceq y$. 
Proof. Consider a Picard sequence $x_{n+1}=S x_{n}$ with initial guess $x_{0}$, as $x_{n+1}=S x_{n} \preceq x_{n}$ for all $n \in\{0\} \cup N$. We will prove that $x_{n} \in \overline{B\left(x_{0}, r\right)}$ for all $n \in N$ by mathematical induction. By using inequality (3), we have

$$
\begin{aligned}
q\left(x_{0}, x_{1}\right) & \leq(1-k)\left[r+q\left(x_{0}, x_{0}\right)\right] \\
& \leq r+q\left(x_{0}, x_{0}\right) .
\end{aligned}
$$

Therefore $x_{1} \in \overline{B\left(x_{0}, r\right)}$. Now let $x_{2}, \ldots, x_{j} \in \overline{B\left(x_{0}, r\right)}$ for some $j \in N$. As $x_{n+1} \preceq x_{n}$, so using inequality (2), we obtain

$$
q\left(x_{j}, x_{j+1}\right)=q\left(S x_{j-1}, S x_{j}\right) \leq k q\left(x_{j-1}, x_{j}\right),
$$

which implies that,

$$
q\left(x_{j}, x_{j+1}\right) \leq k^{2} q\left(x_{j-2}, x_{j-1}\right) \leq \cdots \leq k^{j} q\left(x_{0}, x_{1}\right) .
$$

Now

$$
\begin{aligned}
q\left(x_{0}, x_{j+1}\right) \leq & q\left(x_{0}, x_{1}\right)+\cdots+q\left(x_{j}, x_{j+1}\right) \\
& -\left[q\left(x_{1}, x_{1}\right)+\cdots+q\left(x_{j}, x_{j}\right)\right] \\
\leq & q\left(x_{0}, x_{1}\right)\left[1+\cdots+k^{j-1}+k^{j}\right]
\end{aligned}
$$

(by inequality (6)),

$$
q\left(x_{0}, x_{j+1}\right) \leq(1-k)\left[r+q\left(x_{0}, x_{0}\right)\right] \frac{\left(1-k^{j+1}\right)}{1-k}
$$

(by inequality (3)) .

Thus $x_{j+1} \in \overline{B\left(x_{0}, r\right)}$. Hence $x_{n} \in \overline{B\left(x_{0}, r\right)}$ for all $n \in N$. Also $x_{n+1} \preceq x_{n}$ for all $n \in N$. It implies that

$$
q\left(x_{n}, x_{n+1}\right) \leq k^{n} q\left(x_{0}, x_{1}\right) \quad \text { for all } n \in N .
$$

It follows that

$$
\begin{aligned}
q\left(x_{n}, x_{n+i}\right) & \leq q\left(x_{n}, x_{n+1}\right)+\cdots+q\left(x_{n+i-1}, x_{n+i}\right) \\
& \leq k^{n} q\left(x_{0}, x_{1}\right)\left[1+\cdots+k^{i-2}+k^{i-1}\right] \\
\text { as } n \longrightarrow 0 & \longrightarrow \infty .
\end{aligned}
$$

Notice that the sequence $\left\{x_{n}\right\}$ is a 0 -Cauchy sequence in $\left(\overline{B\left(x_{0}, r\right)}, q\right)$. As $\overline{B\left(x_{0}, r\right)}$ is closed so is 0-complete. Therefore there exists a point $x^{*} \in \overline{B\left(x_{0}, r\right)}$ with

$$
q\left(x^{*}, x^{*}\right)=\lim _{n \rightarrow \infty} q\left(x_{n}, x^{*}\right)=\lim _{n \rightarrow \infty} q\left(x^{*}, x_{n}\right)=0 .
$$

Now,

$$
q\left(x^{*}, S x^{*}\right) \leq q\left(x^{*}, x_{n}\right)+q\left(S x_{n-1}, S x^{*}\right)-q\left(x_{n}, x_{n}\right) .
$$

On taking limit as $n \rightarrow \infty$ and using the fact that $x^{*} \preceq x_{n} \preceq$ $x_{n-1}$, when $x_{n} \rightarrow x^{*}$, we have,

$$
q\left(x^{*}, S x^{*}\right) \leq \lim _{n \rightarrow \infty}\left[q\left(x^{*}, x_{n}\right)+k q\left(x_{n-1}, x^{*}\right)\right] .
$$

Then by inequality (10), we have

$$
q\left(x^{*}, S x^{*}\right) \leq 0
$$

Similarly,

$$
q\left(S x^{*}, x^{*}\right) \leq 0
$$

and hence $x^{*}=S x^{*}$.

Uniqueness. Let $y$ be another point in $\overline{B\left(x_{0}, r\right)}$ such that $y=$ Sy. If $x^{*}$ and $y$ are comparable, then

$$
q\left(x^{*}, y\right)=q\left(S x^{*}, S y\right) \leq k q\left(x^{*}, y\right) .
$$

This shows that $x^{*}=y$. Now if $x^{*}$ and $y$ are not comparable then there exists a point $z \in \overline{B\left(x_{0}, r\right)}$ which is lower bound of both $x^{*}$ and $y$, that is, $z \preceq x^{*}$ and $z \preceq y$. Moreover by assumption $z \preceq x^{*} \preceq x_{n} \cdots \preceq x_{0}$. Now we will prove that $S^{n} z \in \overline{B\left(x_{0}, r\right)}$ :

$$
\begin{aligned}
q\left(x_{0}, S z\right) & \leq q\left(x_{0}, x_{1}\right)+q\left(x_{1}, S z\right)-q\left(x_{1}, x_{1}\right) \\
& \leq(1-k)\left[r+q\left(x_{0}, x_{0}\right)\right]+k q\left(x_{0}, z\right)
\end{aligned}
$$

(by inequality (2) and inequality (3)),

$$
\begin{aligned}
q\left(x_{0}, S z\right) \leq & (1-k) r+(1-k) q\left(x_{0}, x_{0}\right)+k\left[r+q\left(x_{0}, x_{0}\right)\right] \\
= & r-r k+q\left(x_{0}, x_{0}\right)-k q\left(x_{0}, x_{0}\right)+r k \\
& +k q\left(x_{0}, x_{0}\right) \\
= & r+q\left(x_{0}, x_{0}\right) .
\end{aligned}
$$

It follows that $S z \in \overline{B\left(x_{0}, r\right)}$. Now let $S^{j} z \in \overline{B\left(x_{0}, r\right)}$

$$
\begin{aligned}
q\left(x_{0}, S^{j+1} z\right) & \leq q\left(x_{0}, x_{1}\right)+q\left(x_{1}, S^{j+1} z\right)-q\left(x_{1}, x_{1}\right) \\
& \leq(1-k)\left[r+q\left(x_{0}, x_{0}\right)\right]+k q\left(x_{0}, S^{j} z\right)
\end{aligned}
$$

(by inequality (2) and inequality (3)),

$$
\begin{aligned}
q\left(x_{0}, S^{j+1} z\right) \leq & (1-k) r+(1-k) q\left(x_{0}, x_{0}\right) \\
& +k\left[r+q\left(x_{0}, x_{0}\right)\right] \\
\leq & r-r k+q\left(x_{0}, x_{0}\right)-k q\left(x_{0}, x_{0}\right) \\
& +r k+k q\left(x_{0}, x_{0}\right) \\
\leq & r+q\left(x_{0}, x_{0}\right) .
\end{aligned}
$$

It follows that $S^{j+1} z \in \overline{B\left(x_{0}, r\right)}$. Hence $S^{n} z \in \overline{B\left(x_{0}, r\right)}$ for all $n \in N$. Now as $S$ is dominated, it follows that $S^{n-1} z \preceq$ $S^{n-2} z \preceq \cdots \preceq z \preceq x^{*}$ and $S^{n-1} z \preceq y$ for all $n \in N$, which 
further implies $S^{n-1} z \preceq S^{n} x^{*}$ and $S^{n-1} z \preceq S^{n} y$ for all $n \in N$ as $S^{n} x^{*}=x^{*}$ and $S^{n} y=y$ for all $n \in N$ :

$$
\begin{aligned}
q\left(x^{*}, y\right)= & q\left(S^{n} x^{*}, S^{n} y\right) \\
\leq & q\left(S^{n} x^{*}, S^{n-1} z\right)+q\left(S^{n-1} z, S^{n} y\right) \\
& -q\left(S^{n-1} z, S^{n-1} z\right) \\
\leq & k q\left(S^{n-1} x^{*}, S^{n-2} z\right)+k q\left(S^{n-2} z, S^{n-1} y\right) \\
\quad(\because \text { by inequality }(2)) & \\
\vdots & \quad k^{n-2} q\left(x^{*}, S z\right)+k^{n-2} q(S z, y) \longrightarrow 0
\end{aligned}
$$

Hence $x^{*}=y$.

Example 11. Let $X=[0,+\infty) \cap Q$ be endowed with order $x \preceq y$ if $q(x, x) \leq q(y, y)$ and let $q: X \times X \rightarrow R^{+}$be the 0 -complete ordered quasi-partial metric on $X$ defined by $q(x, y)=\max \{y-x, 0\}+x$. Define

$$
S x= \begin{cases}\frac{1}{10} x & \text { if } x \in[0,1] \cap X \\ x-\frac{4}{9} & \text { if } x \in(1, \infty) \cap X .\end{cases}
$$

Clearly, $S$ is dominated mapping. Take $x_{0}=1 / 2, r=1 / 2$; then $\overline{B\left(x_{0}, r\right)}=[0,1] \cap X$; we have $q\left(x_{0}, x_{0}\right)=1 / 2, k=4 / 9$ with

$$
\begin{aligned}
(1-k)\left[r+q\left(x_{0}, x_{0}\right)\right] & =\left(1-\frac{4}{9}\right)\left[\frac{1}{2}+\frac{1}{2}\right]=\frac{5}{9}, \\
q\left(x_{0}, S x_{0}\right) & =q\left(\frac{1}{2}, S\left(\frac{1}{2}\right)\right) \\
& =q\left(\frac{1}{2}, \frac{1}{20}\right)=\frac{1}{2}<\frac{5}{9} .
\end{aligned}
$$

Also if $x, y \in(1, \infty) \cap X$, then,

$$
\begin{aligned}
q(S x, S y) & =\max \left\{y-\frac{4}{9}-x+\frac{4}{9}, 0\right\}+x-\frac{4}{9} \\
& =\max \{y-x, 0\}+x-\frac{4}{9} \\
& \geq \frac{4}{9}[\max \{y-x, 0\}+x]=k q(x, y) .
\end{aligned}
$$

So the contractive condition does not hold on $X$ in each case.

Now if

$$
x, y \in \overline{B\left(x_{0}, r\right)} \cap X
$$

then,

$$
\begin{aligned}
q(S x, S y) & =\max \left\{\frac{1}{10} y-\frac{1}{10} x, 0\right\}+\frac{1}{10} x \\
& =\frac{1}{10} q(x, y)<\frac{4}{9} q(x, y) .
\end{aligned}
$$

Therefore, all the conditions of Theorem 13 are satisfied. Moreover, 0 is the unique fixed point of $S$ and $q(0,0)=0$.

In Theorem 10, the condition (3) is imposed to restrict the condition (2) only for $x, y$ in $\overline{B\left(x_{0}, r\right)}$ and Example 11 explains the utility of this restriction. However, the following result relaxes the condition (3) but imposes the condition (2) for all comparable elements in the whole space $X$.

Theorem 12. Let $(X, \preceq, q)$ be a 0 -complete ordered quasipartial metric space, $S: X \rightarrow X$ a dominated map, and $x_{0}$ an arbitrary point in $X$. Suppose there exists $k \in[0,1)$ with

$$
\begin{aligned}
& q(S x, S y) \leq k q(x, y), \\
& \quad \text { for all comparable elements } x, y \text { in } X .
\end{aligned}
$$

If, for a nonincreasing sequence $\left\{x_{n}\right\}$ in $X,\left\{x_{n}\right\} \rightarrow u$ implies that $u \preceq x_{n}$, then there exists a point $x^{*}$ in $X$ such that $x^{*}=S x^{*}$ and $q\left(x^{*}, x^{*}\right)=0$. Moreover, $x^{*}$ is unique, if for every pair of elements $x, y$ in $X$, there exists a point $z \in X$ such that $z \preceq x$ and $z \preceq y$.

In Theorem 10, the existence of a lower bound and for a nonincreasing sequence $\left\{x_{n}\right\}$ in $X,\left\{x_{n}\right\} \rightarrow u$ implies that $u \preceq x_{n}$ are imposed to restrict the condition (2) only for comparable elements. However, the following result relaxes these conditions but imposes the condition (2) for all elements in $\overline{B\left(x_{0}, r\right)}$.

Theorem 13. Let $(X, q)$ be a 0 -complete partial metric space, $S: X \rightarrow X a$ map, and $x_{0}$ an arbitrary point in $X$. Suppose there exists $k \in[0,1)$ with

$$
\begin{aligned}
& q(S x, S y) \leq k q(x, y), \\
& \text { for all elements } x, y \text { in } \overline{B\left(x_{0}, r\right)}, \\
& q\left(x_{0}, S x_{0}\right) \leq(1-k)\left[r+q\left(x_{0}, x_{0}\right)\right] .
\end{aligned}
$$

Then there exists a unique point $x^{*}$ in $\overline{B\left(x_{0}, r\right)}$ such that $x^{*}=$ $S x^{*}$. Further $q\left(x^{*}, x^{*}\right)=0$.

Metric version of Theorem 10 is given below.

Theorem 14. Let $(X, \preceq, d)$ be a complete ordered metric space, $S: X \rightarrow X$ a dominated map, and $x_{0}$ an arbitrary point in $X$. Suppose that there exists $k \in[0,1)$ such that

$$
d(S x, S y) \leq k d(x, y)
$$

$$
\text { for all comparable elements } x, y \text { in } \overline{B\left(x_{0}, r\right)} \text {, }
$$

$$
d\left(x_{0}, S x_{0}\right) \leq(1-k) r \text {. }
$$


If, for a nonincreasing sequence $\left\{x_{n}\right\}$ in $\overline{B\left(x_{0}, r\right)},\left\{x_{n}\right\} \rightarrow u$ implies that $u \leq x_{n}$, then there exists a point $x^{*}$ in $\overline{B\left(x_{0}, r\right)}$ such that $x^{*}=S x^{*}$ and $q\left(x^{*}, x^{*}\right)=0$. Moreover, $x^{*}$ is unique, if for every pair of elements $x, y$ in $X$ there exists a point $z \in X$ such that $z \preceq x$ and $z \preceq y$.

Theorem 15. Let $(X, \preceq, q)$ be a 0 -complete ordered quasipartial metric space, $S: X \rightarrow X$ a dominated map, and $x_{0}$ an arbitrary point in $X$. Suppose that there exists $b \in[0,1 / 2)$ such that

$$
q(S x, S y) \leq b[q(x, S x)+q(y, S y)]
$$

for all comparable elements $x, y$ in $\overline{B\left(x_{0}, r\right)}$.

And

$$
q\left(x_{0}, S x_{0}\right) \leq(1-k)\left[r+q\left(x_{0}, x_{0}\right)\right],
$$

where $k=b /(1-b)$. If, for a nonincreasing sequence $\left\{x_{n}\right\}$ in $\overline{B\left(x_{0}, r\right)},\left\{x_{n}\right\} \rightarrow u$ implies that $u \leq x_{n}$, then there exists a point $x^{*}$ in $\overline{B\left(x_{0}, r\right)}$ such that $x^{*}=S x^{*}$ and $q\left(x^{*}, x^{*}\right)=0$. Moreover, $x^{*}$ is unique, if for any two points $x, y$ in $\overline{B\left(x_{0}, r\right)}$ there exists a point $z \in \overline{B\left(x_{0}, r\right)}$ such that $z \preceq x$ and $z \preceq y$, and

$q\left(x_{0}, S x_{0}\right)+q(z, S z) \leq q\left(x_{0}, z\right)+q\left(S x_{0}, S z\right) \quad$ for all $z \leq S x_{0}$.

Proof. Consider a Picard sequence $x_{n+1}=S x_{n}$ with initial guess $x_{0}$, as $x_{n+1}=S x_{n} \leq x_{n}$ for all $n \in\{0\} \cup N$. We will prove that $x_{n} \in \overline{B\left(x_{0}, r\right)}$ for all $n \in N$ by mathematical induction. By using inequality (28), we have

$$
\begin{aligned}
q\left(x_{0}, x_{1}\right) & \leq(1-k)\left[r+q\left(x_{0}, x_{0}\right)\right] \\
& \leq r+q\left(x_{0}, x_{0}\right) .
\end{aligned}
$$

Therefore $x_{1} \in \overline{B\left(x_{0}, r\right)}$. Now let $x_{2}, \ldots, x_{j} \in \overline{B\left(x_{0}, r\right)}$ for some $j \in N$. As $x_{j+1} \preceq x_{j}$, so using inequality (27), we obtain

$$
\begin{aligned}
q\left(x_{j}, x_{j+1}\right) & =q\left(S x_{j-1}, S x_{j}\right) \\
& \leq b\left[q\left(x_{j-1}, x_{j}\right)+q\left(x_{j}, x_{j+1}\right)\right] \\
& \leq k q\left(x_{j-1}, x_{j}\right),
\end{aligned}
$$

which implies that

$$
q\left(x_{j}, x_{j+1}\right) \leq k^{2} q\left(x_{j-2}, x_{j-1}\right) \leq \cdots \leq k^{j} q\left(x_{0}, x_{1}\right) .
$$

Now,

$$
\begin{aligned}
q\left(x_{0}, x_{j+1}\right) \leq & q\left(x_{0}, x_{1}\right)+\cdots+q\left(x_{j}, x_{j+1}\right) \\
& -\left[q\left(x_{1}, x_{1}\right)+\cdots+q\left(x_{j}, x_{j}\right)\right] \\
\leq & q\left(x_{0}, x_{1}\right)\left[1+\cdots+k^{j-1}+k^{j}\right]
\end{aligned}
$$

(by inquality (32)),

$$
q\left(x_{0}, x_{j+1}\right) \leq(1-k)\left[r+q\left(x_{0}, x_{0}\right)\right] \frac{\left(1-k^{j+1}\right)}{1-k}
$$

(by inquality (28)) .

Thus $x_{j+1} \in \overline{B\left(x_{0}, r\right)}$. Hence $x_{n} \in \overline{B\left(x_{0}, r\right)}$ for all $n \in N$. Also $x_{n+1} \leq x_{n}$ for all $n \in N$. It implies that

$$
q\left(x_{n}, x_{n+1}\right) \leq k^{n} q\left(x_{0}, x_{1}\right) \quad \text { for all } n \in N .
$$

It follows that

$$
\begin{aligned}
q\left(x_{n}, x_{n+i}\right) \leq q\left(x_{n}, x_{n+1}\right)+\cdots+q\left(x_{n+i-1}, x_{n+i}\right) & \\
q\left(x_{n}, x_{n+i}\right) \leq k^{n} q\left(x_{0}, x_{1}\right)\left[1+\cdots+k^{i-2}+k^{i-1}\right] & \rightarrow 0 \\
\text { as } n & \rightarrow \infty .
\end{aligned}
$$

Notice that the sequence $\left\{x_{n}\right\}$ is a 0 -Cauchy sequence in $\left(\overline{B\left(x_{0}, r\right)}, q\right)$. As $\overline{B\left(x_{0}, r\right)}$ is closed, so is 0 -complete. Therefore there exists a point $x^{*} \in \overline{B\left(x_{0}, r\right)}$ with

$$
q\left(x^{*}, x^{*}\right)=\lim _{n \rightarrow \infty} q\left(x_{n}, x^{*}\right)=\lim _{n \rightarrow \infty} q\left(x^{*}, x_{n}\right)=0 .
$$

Now,

$$
q\left(x^{*}, S x^{*}\right) \leq q\left(x^{*}, x_{n}\right)+q\left(S x_{n-1}, S x^{*}\right)-q\left(x_{n}, x_{n}\right) .
$$

On taking limit as $n \rightarrow \infty$ and using the fact that $x^{*} \preceq x_{n} \preceq$ $x_{n-1}$, when $x_{n} \rightarrow x^{*}$, we have,

$$
\begin{aligned}
& q\left(x^{*}, S x^{*}\right) \leq \lim _{n \rightarrow \infty}\left[q\left(x^{*}, x_{n}\right)\right. \\
&\left.+b\left\{q\left(x_{n-1}, S x_{n-1}\right)+q\left(x^{*}, S x^{*}\right)\right\}\right] \\
& \leq \lim _{n \rightarrow \infty} b\left\{k^{n-1} q\left(x_{0}, x_{1}\right)+q\left(x^{*}, S x^{*}\right)\right\} \\
& \leq \lim _{n \rightarrow \infty} k^{n} q\left(x_{0}, x_{1}\right) \leq 0 .
\end{aligned}
$$

Similarly,

$$
q\left(S x^{*}, x^{*}\right) \leq 0,
$$

and hence $x^{*}=S x^{*}$. Now,

$$
\begin{aligned}
q\left(x^{*}, x^{*}\right) & =q\left(S x^{*}, S x^{*}\right) \\
& \leq b\left\{q\left(x^{*}, S x^{*}\right)+q\left(x^{*}, S x^{*}\right)\right\}
\end{aligned}
$$$$
(1-2 b) q\left(x^{*}, x^{*}\right) \leq 0 .
$$

This implies that

$$
q\left(x^{*}, x^{*}\right)=0 .
$$


Uniqueness. Let $y$ be another point in $\overline{B\left(x_{0}, r\right)}$ such that $y=$ Sy. If $x^{*}$ and $y$ are comparable, then

$$
\begin{aligned}
q\left(x^{*}, y\right) & =q\left(S x^{*}, S y\right) \\
& \leq b\left[q\left(x^{*}, S x^{*}\right)+q(y, S y)\right] \\
& =b\left[q\left(x^{*}, x^{*}\right)+q(y, y)\right] \\
& =b q(y, y) \leq q(y, y) .
\end{aligned}
$$

Using the fact that $q(y, y) \leq q\left(x^{*}, y\right)$, we have $q\left(x^{*}, y\right)=0$. Similarly, $q\left(y, x^{*}\right)=0$. Now if $x^{*}$ and $y$ are not comparable to then there exists a point $z \in \overline{B\left(x_{0}, r\right)}$ which is a lower bound of both $x^{*}$ and $y$. Moreover by assumption $S z \preceq z \preceq x^{*} \preceq$ $x_{n} \cdots \preceq x_{0}$. Now by using inequality (27), we have

$$
\begin{aligned}
q\left(S x_{0}, S z\right) & \leq b\left[q\left(x_{0}, x_{1}\right)+q(z, S z)\right] \\
& \leq b\left[q\left(x_{0}, z\right)+q\left(x_{1}, S z\right)\right]
\end{aligned}
$$

(by inequality (29)),

$$
\begin{aligned}
q\left(x_{1}, S z\right) & \leq k q\left(x_{0}, z\right) . \\
q\left(x_{0}, S z\right) & \leq q\left(x_{0}, x_{1}\right)+q\left(x_{1}, S z\right)-q\left(x_{1}, x_{1}\right) \\
& \leq q\left(x_{0}, x_{1}\right)+k q\left(x_{0}, z\right) \quad(\text { by inequality }(43)), \\
q\left(x_{0}, S z\right) & \leq(1-k)\left[r+q\left(x_{0}, x_{0}\right)\right]+k\left[r+q\left(x_{0}, x_{0}\right)\right] \\
& =r+q\left(x_{0}, x_{0}\right) .
\end{aligned}
$$

It follows that $S z \in \overline{B\left(x_{0}, r\right)}$. Now, we will prove that $S^{n} z \in$ $\overline{B\left(x_{0}, r\right)}$, by using mathematical induction to apply inequality (27). Let $S^{2} z, \ldots, S^{j} z \in \overline{B\left(x_{0}, r\right)}$ for some $j \in N$. As $S^{j} z \preceq$ $S^{j-1} z \preceq \cdots \preceq z \preceq x^{*} \preceq x_{n} \cdots \preceq x_{0}$; then,

$$
\begin{aligned}
q\left(S^{j} z, S^{j+1} z\right) & =q\left(S\left(S^{j-1} z\right), S\left(S^{j} z\right)\right) \\
& \leq b\left[q\left(S^{j-1} z, S^{j} z\right)+q\left(S^{j} z, S^{j+1} z\right)\right],
\end{aligned}
$$

which implies that

$$
\begin{aligned}
q\left(S^{j} z, S^{j+1} z\right) & \leq k q\left(S^{j-1} z, S^{j} z\right) \\
& \leq k^{2} q\left(S^{j-2} z, S^{j-1} z\right) \leq \cdots \leq k^{j} q(z, S z) .
\end{aligned}
$$

Now,

$$
\begin{aligned}
q\left(x_{j+1}, S^{j+1} z\right) & =q\left(S x_{j}, S\left(S^{j} z\right)\right) \\
& \leq b\left[q\left(x_{j}, S x_{j}\right)+q\left(S^{j} z, S^{j+1} z\right)\right] \\
& \leq b\left[k^{j} q\left(x_{0}, x_{1}\right)+k^{j} q(z, S z)\right]
\end{aligned}
$$

(by inequality (32) and inequality (46))

$$
\leq b k^{j}\left[q\left(x_{0}, z\right)+q\left(x_{1}, S z\right)\right]
$$

(by inequality (29))

$$
\leq b k^{j}\left[q\left(x_{0}, z\right)+k q\left(x_{0}, z\right)\right]=k^{j+1} q\left(x_{0}, z_{0}\right) \text {. }
$$

Now,

$$
\begin{aligned}
q\left(x_{0}, S^{j+1} z\right) \leq & q\left(x_{0}, x_{1}\right)+q\left(x_{1}, x_{2}\right)+\cdots+q\left(x_{j}, x_{j+1}\right) \\
& +q\left(x_{j+1}, S^{j+1} z\right) \\
\leq & q\left(x_{0}, x_{1}\right)+k q\left(x_{0}, x_{1}\right)+\cdots+k^{j+1} q\left(x_{0}, z\right),
\end{aligned}
$$

(by inequality (32) and inequality (47))

$$
\begin{array}{r}
q\left(x_{0}, S^{j+1} z\right) \leq q\left(x_{0}, x_{1}\right)\left[1+k+\cdots k^{j}\right]+k^{j+1} r, \\
\left(\text { as } z \in \overline{B\left(x_{0}, r\right)}\right) \\
q\left(x_{0}, S^{j+1} z\right) \leq(1-k) r \frac{\left(1-k^{j+1}\right)}{1-k}+k^{j+1} r=r .
\end{array}
$$

It follows that $S^{j+1} z \in \overline{B\left(x_{0}, r\right)}$ and hence $S^{n} z \in \overline{B\left(x_{0}, r\right)}$. Now inequality (46) can be written as

$$
q\left(S^{n} z, S^{n+1} z\right) \leq k^{n} q(z, S z) \rightarrow 0 \text { as } n \rightarrow \infty .
$$

Now,

$$
\begin{aligned}
q\left(x^{*}, y\right)= & q\left(S x^{*}, S y\right) \\
\leq & q\left(S x^{*}, S^{n+1} z\right)+q\left(S^{n+1} z, S y\right) \\
\leq & b\left[q\left(x^{*}, S x^{*}\right)+q\left(S^{n} z, S^{n+1} z\right)\right] \\
& +b\left[q\left(S^{n} z, S^{n+1} z\right)+q(y, S y)\right] \\
\leq & b q\left(x^{*}, x^{*}\right)+2 b q\left(S^{n} z, S^{n+1} z\right)+b q(y, y) \\
\leq & b q(y, y) \leq q(y, y)
\end{aligned}
$$

(by inequality (41) and inequality (49)).

Using the fact that $q(y, y) \leq q\left(x^{*}, y\right)$, we have $q\left(x^{*}, y\right)=0$. Similarly, $q\left(y, x^{*}\right)=0$. Hence $x^{*}=y$.

In Theorem 15, the conditions (29), the existence of a lower bound and for a nonincreasing sequence $\left\{x_{n}\right\}$ in $X$, $\left\{x_{n}\right\} \rightarrow u$ implies that $u \preceq x_{n}$ are imposed to restrict the condition (27) only for comparable elements. However, the following result relaxes these conditions but imposes the condition (27) for all elements in $\overline{B\left(x_{0}, r\right)}$.

Theorem 16. Let $\left(X, d_{q}\right)$ be a complete dislocated quasimetric space, $S: X \rightarrow X$ a map, and $x_{0}$ an arbitrary point in $X$. Suppose there exists $k \in[0,1 / 2)$ with

$$
d_{q}(S x, S y) \leq k\left[d_{q}(x, S x)+d_{q}(y, S y)\right]
$$

for all elements $x, y$ in $\overline{B\left(x_{0}, r\right)}$ and

$$
d_{q}\left(x_{0}, S x_{0}\right) \leq(1-\theta) r,
$$

where $\theta=k /(1-k)$. Then there exists a unique point $x^{*}$ in $\overline{B\left(x_{0}, r\right)}$ such that $x^{*}=S x^{*}$ and $d_{q}\left(x^{*}, x^{*}\right)=0$. 
In Theorem 10, the conditions (28) and (29) are imposed to restrict the condition (27) only for comparable elements. However, the following result relaxes these conditions but imposes the condition (27) for all elements in $X$.

Theorem 17. Let $(X, \preceq, q)$ be a 0-complete ordered quasipartial metric space and let $S: X \rightarrow X$ be a dominated map. Suppose that there exists $b \in[0,1 / 2)$ such that

$$
q(S x, S y) \leq b[q(x, S x)+q(y, S y)]
$$

for all comparable elements $x, y$ in $X$. If, for a nonincreasing sequence $\left\{x_{n}\right\}$ in $X,\left\{x_{n}\right\} \rightarrow u$ implies that $u \leq x_{n}$, then there exists a point $x^{*}$ in $X$ such that $x^{*}=S x^{*}$ and $q\left(x^{*}, x^{*}\right)=0$. Moreover, $x^{*}$ is unique, if for any two points $x, y$ in $\overline{B\left(x_{0}, r\right)}$ there exists a point $z \in \overline{B\left(x_{0}, r\right)}$ such that $z \preceq x$ and $z \preceq y$.

Theorem 18. Let $(X, \preceq, q)$ be a 0 -complete ordered quasipartial metric space, $S: X \rightarrow X$ a dominated map, and $x_{0}$ an arbitrary point in $X$. Suppose that there exists $c \in[0,1 / 2)$ such that

$$
q(S x, S y) \leq c[q(x, S y)+q(S x, y)]
$$

for all comparable elements $x, y$ in $\overline{B\left(x_{0}, r\right)}$.

And

$$
q\left(x_{0}, S x_{0}\right) \leq(1-k)\left[r+q\left(x_{0}, x_{0}\right)\right],
$$

where $k=c /(1-c)$. If, for a nonincreasing sequence $\left\{x_{n}\right\}$ in $\overline{B\left(x_{0}, r\right)},\left\{x_{n}\right\} \rightarrow u$ implies that $u \leq x_{n}$, then there exists a point $x^{*}$ in $\overline{B\left(x_{0}, r\right)}$ such that $x^{*}=S x^{*}$. Further $q\left(x^{*}, x^{*}\right)=0$.

Proof. Consider a Picard sequence $x_{n+1}=S x_{n}$ with initial guess $x_{0}$. As $x_{n+1}=S x_{n} \leq x_{n}$ for all $n \in\{0\} \cup N$. We will prove that $x_{n} \in \overline{B\left(x_{0}, r\right)}$ for all $n \in N$ by mathematical induction. By using inequality (55), we have

$$
q\left(x_{0}, x_{1}\right) \leq r+q\left(x_{0}, x_{0}\right) .
$$

Therefore $x_{1} \in \overline{B\left(x_{0}, r\right)}$. Now let $x_{2}, \ldots, x_{j} \in \overline{B\left(x_{0}, r\right)}$ for some $j \in N$. As $x_{n+1} \leq x_{n}$, so using inequality (54), we obtain

$$
\begin{aligned}
q\left(x_{j}, x_{j+1}\right) \leq c[ & {\left[\left(x_{j-1}, x_{j}\right)+q\left(x_{j}, x_{j+1}\right)\right.} \\
& \left.-q\left(x_{j}, x_{j}\right)+q\left(x_{j}, x_{j}\right)\right] \\
\leq & k q\left(x_{j-1}, x_{j}\right),
\end{aligned}
$$

which implies that

$$
q\left(x_{j}, x_{j+1}\right) \leq k^{2} q\left(x_{j-2}, x_{j-1}\right) \leq \cdots \leq k^{j} q\left(x_{0}, x_{1}\right) .
$$

Now

$$
\begin{aligned}
q\left(x_{0}, x_{j+1}\right) \leq & q\left(x_{0}, x_{1}\right)+\cdots+q\left(x_{j}, x_{j+1}\right) \\
& -\left[q\left(x_{1}, x_{1}\right)+\cdots+q\left(x_{j}, x_{j}\right)\right] \\
q\left(x_{0}, x_{j+1}\right) \leq & (1-k)\left[r+q\left(x_{0}, x_{0}\right)\right] \frac{\left(1-k^{j+1}\right)}{1-k}
\end{aligned}
$$

(by inequality (55)).
Thus $x_{j+1} \in \overline{B\left(x_{0}, r\right)}$. Hence $x_{n} \in \overline{B\left(x_{0}, r\right)}$ for all $n \in N$. Also $x_{n+1} \leq x_{n}$ for all $n \in N$. It implies that

$$
q\left(x_{n}, x_{n+1}\right) \leq k^{n} q\left(x_{0}, x_{1}\right) \quad \text { for all } n \in N .
$$

It follows that

$$
\begin{aligned}
q\left(x_{n}, x_{n+i}\right) \leq q\left(x_{n}, x_{n+1}\right)+\cdots+q\left(x_{n+i-1}, x_{n+i}\right) & \\
q\left(x_{n}, x_{n+i}\right) \leq k^{n} q\left(x_{0}, x_{1}\right)\left[1+\cdots+k^{i-2}+k^{i-1}\right] & \rightarrow 0 \\
\text { as } n & \rightarrow \infty .
\end{aligned}
$$

Notice that the sequence $\left\{x_{n}\right\}$ is a 0 -Cauchy sequence in $\left(\overline{B\left(x_{0}, r\right)}, q\right)$. As $\overline{B\left(x_{0}, r\right)}$ is closed so is 0 -complete. Therefore there exists a point $x^{*} \in \overline{B\left(x_{0}, r\right)}$ with

$$
q\left(x^{*}, x^{*}\right)=\lim _{n \rightarrow \infty} q\left(x_{n}, x^{*}\right)=\lim _{n \rightarrow \infty} q\left(x^{*}, x_{n}\right)=0 .
$$

Now,

$$
q\left(x^{*}, S x^{*}\right) \leq q\left(x^{*}, x_{n}\right)+q\left(S x_{n-1}, S x^{*}\right)-q\left(x_{n}, x_{n}\right) .
$$

On taking limit as $n \rightarrow \infty$ and using the fact that $x^{*} \leq x_{n} \preceq$ $x_{n-1}$, when $x_{n} \rightarrow x^{*}$, we have

$$
\begin{array}{r}
q\left(x^{*}, S x^{*}\right) \leq \lim _{n \rightarrow \infty}\left[q\left(x^{*}, x_{n}\right)\right. \\
+c\left\{q\left(x_{n-1}, S x^{*}\right)+q\left(x_{n}, x^{*}\right)\right\} \\
\leq \lim _{n \rightarrow \infty}\left[c \left\{q\left(x_{n-1}, x^{*}\right)+q\left(x^{*}, S x^{*}\right)\right.\right. \\
\left.\left.-q\left(x^{*}, x^{*}\right)+q\left(x_{n}, x^{*}\right)\right\}\right] \\
\left.(1-c) q\left(x^{*}, S x^{*}\right) \leq 0 \quad \text { (by inequality }(62)\right) .
\end{array}
$$

Similarly,

$$
q\left(S x^{*}, x^{*}\right) \leq 0
$$

and hence $x^{*}=S x^{*}$.

Remark 19. We can obtain the partial metric, quasi-metric, and metric version of all theorems which are still not present in the literature.

\section{Conflict of Interests}

The authors declare that they have no competing interests.

\section{References}

[1] M. Abbas, M. Arshad, and A. Azam, "Fixed points of asymptotically regular mappings in complex-valued metric spaces," Georgian Mathematical Journal, vol. 20, no. 2, pp. 213-221, 2013.

[2] J. Ahmad, M. Arshad, and C. Vetro, "On a theorem of Khan in a generalized metric space," International Journal of Analysis, vol. 2013, Article ID 852727, 6 pages, 2013.

[3] M. Arshad, J. Ahmad, and E. Karapinar, "Some common fixed point results in rectangular metric spaces," International Journal of Analysis, vol. 2013, Article ID 307234, 7 pages, 2013. 
[4] K. Leibovic, "The principle of contration mapping in nonlinear and adoptive controle systems," IEEE Transactions on Automatic Control, vol. 9, pp. 393-398, 1964.

[5] G. A. Medrano-Cerda, "A fixed point formulation to parameter estimation problems," in Proceedings of the 26th IEEE Conference on Decision and Control, pp. 1468-1476, 1987.

[6] J. E. Steck, "Convergence of recurrent networks as contraction mappings," Neural Networks, vol. 3, pp. 7-11, 1992.

[7] A. C. M. Ran and M. C. B. Reurings, "A fixed point theorem in partially ordered sets and some applications to matrix equations," Proceedings of the American Mathematical Society, vol. 132, no. 5, pp. 1435-1443, 2004.

[8] J. J. Nieto and R. Rodríguez-López, "Contractive mapping theorems in partially ordered sets and applications to ordinary differential equations," Order, vol. 22, no. 3, pp. 223-239, 2005.

[9] I. Altun and H. Simsek, "Some fixed point theorems on ordered metric spaces and application," Fixed Point Theory and Applications, vol. 2010, Article ID 621492, 17 pages, 2010.

[10] T. G. Bhaskar and V. Lakshmikantham, "Fixed point theorems in partially ordered metric spaces and applications," Nonlinear Analysis: Theory, Methods \& Applications, vol. 65, no. 7, pp. 13791393, 2006.

[11] H. K. Nashine, B. Samet, and C. Vetro, "Monotone generalized nonlinear contractions and fixed point theorems in ordered metric spaces," Mathematical and Computer Modelling, vol. 54, no. 1-2, pp. 712-720, 2011.

[12] S. G. Matthews, "Partial metric topology," Annals of the New York Academy of Sciences, vol. 728, pp. 183-197, 1994.

[13] M. A. Bukatin and S. Yu. Shorina, "Partial metrics and cocontinuous valuations," in Foundations of Software Science and Computation Structure, M. Nivat et al., Ed., vol. 1378 of Lecture Notes in Computer Science, pp. 125-139, Springer, 1998.

[14] I. Altun and A. Erduran, "Fixed point theorems for monotone mappings on partial metric spaces," Fixed Point Theory and Applications, vol. 2011, Article ID 508730, 10 pages, 2011.

[15] D. Paesano and P. Vetro, "Suzuki's type characterizations of completeness for partial metric spaces and fixed points for partially ordered metric spaces," Topology and Its Applications, vol. 159, no. 3, pp. 911-920, 2012.

[16] E. Karapınar, İ. M. Erhan, and A. Öztürk, "Fixed point theorems on quasi-partial metric spaces," Mathematical and Computer Modelling, vol. 57, no. 9-10, pp. 2442-2448, 2013.

[17] S. Romaguera, "A Kirk type characterization of completeness for partial metric spaces," Fixed Point Theory and Applications, vol. 2010, Article ID 493298, 6 pages, 2010.

[18] H. K. Nashine, Z. Kadelburg, S. Radenovic, and J. K. Kim, "Fixed point theorems under Hardy-Rogers contractive conditions on 0-complete ordered partial metric spaces," Fixed Point Theory and Applications, vol. 2012, article 180, 2012.

[19] M. Arshad, A. Shoaib, and I. Beg, "Fixed point of a pair of contractive dominated mappings on a closed ball in an ordered dislocated metric space," Fixed Point Theory and Applications, vol. 2013, article 115, 2013.

[20] A. Azam, S. Hussain, and M. Arshad, "Common fixed points of Chatterjea type fuzzy mappings on closed balls," Neural Computing and Applications, vol. 21, no. 1, supplement, pp. 313-317, 2012.

[21] A. Azam, M. Waseem, and M. Rashid, "Fixed point theorems for fuzzy contractive mappings in quasi-pseudo-metric spaces," Fixed Point Theory and Applications, vol. 2013, article 27, 2013.
[22] M. Abbas and S. Z. Németh, "Finding solutions of implicit complementarity problems by isotonicity of the metric projection," Nonlinear Analysis: Theory, Methods \& Applications, vol. 75, no. 4, pp. 2349-2361, 2012.

[23] E. Kryeyszig, Introductory Functional Analysis with Applications, John Wiley \& Sons, New York, NY, USA, 1989. 


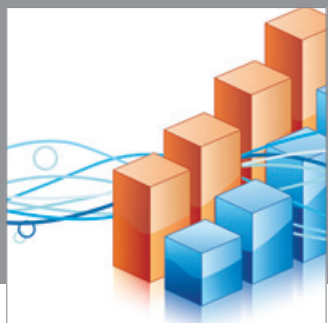

Advances in

Operations Research

mansans

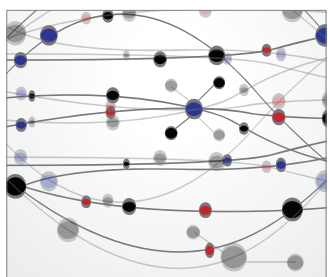

The Scientific World Journal
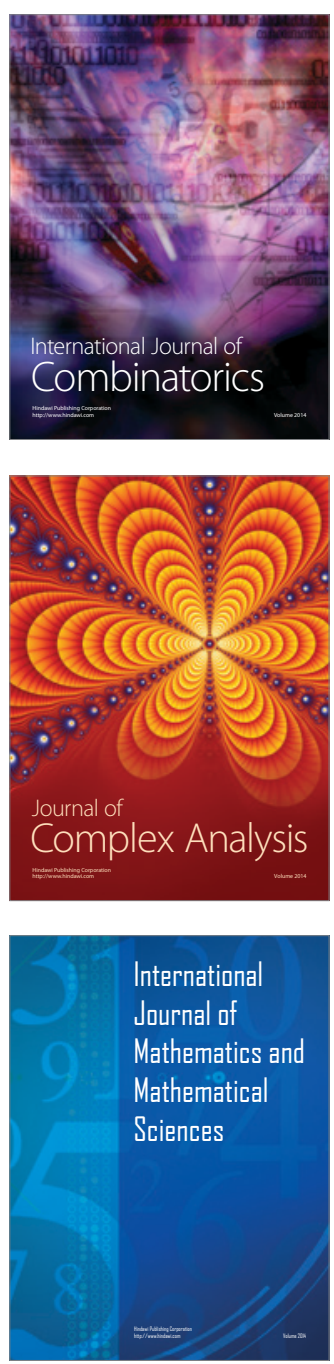
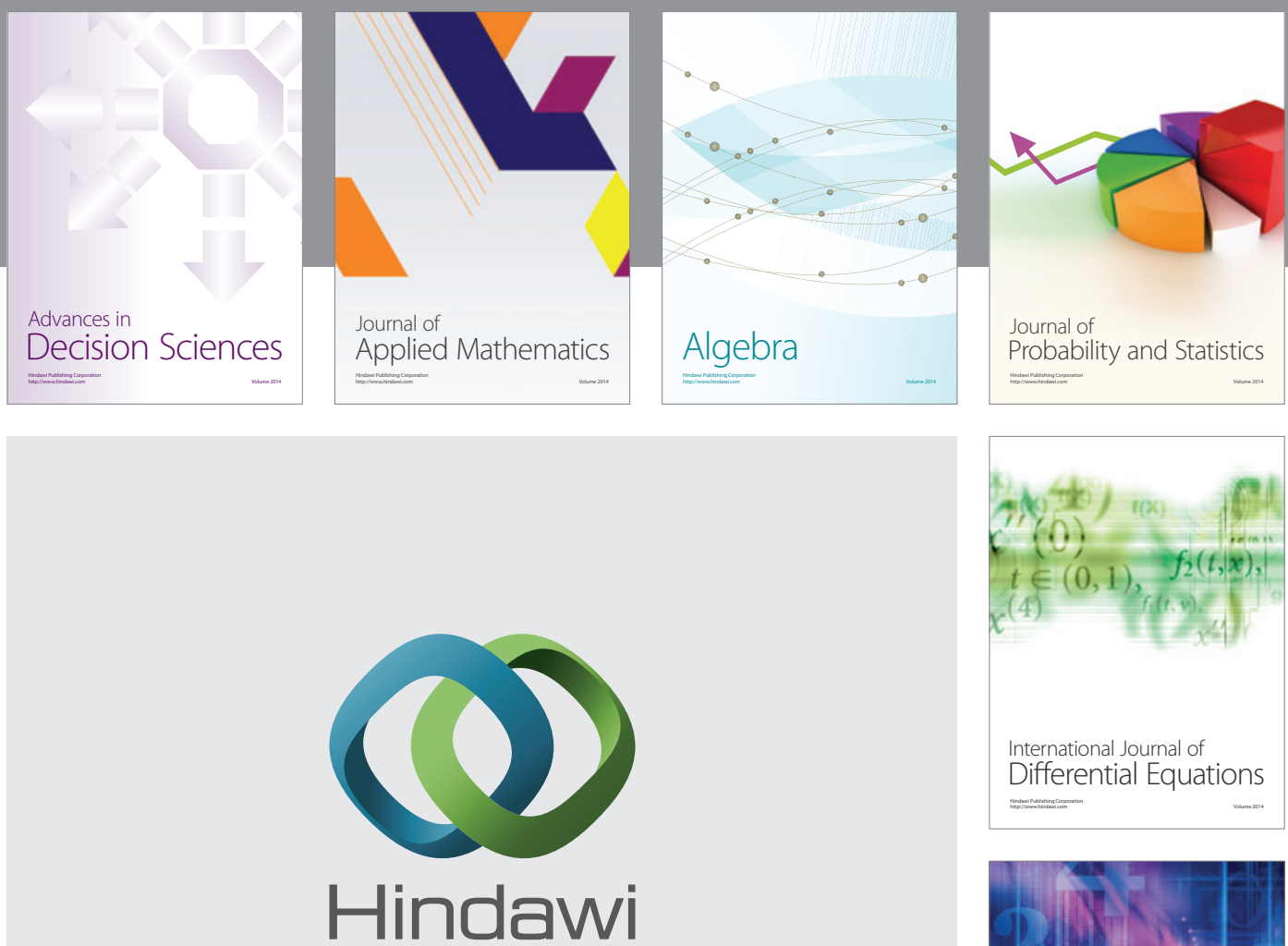

Submit your manuscripts at http://www.hindawi.com
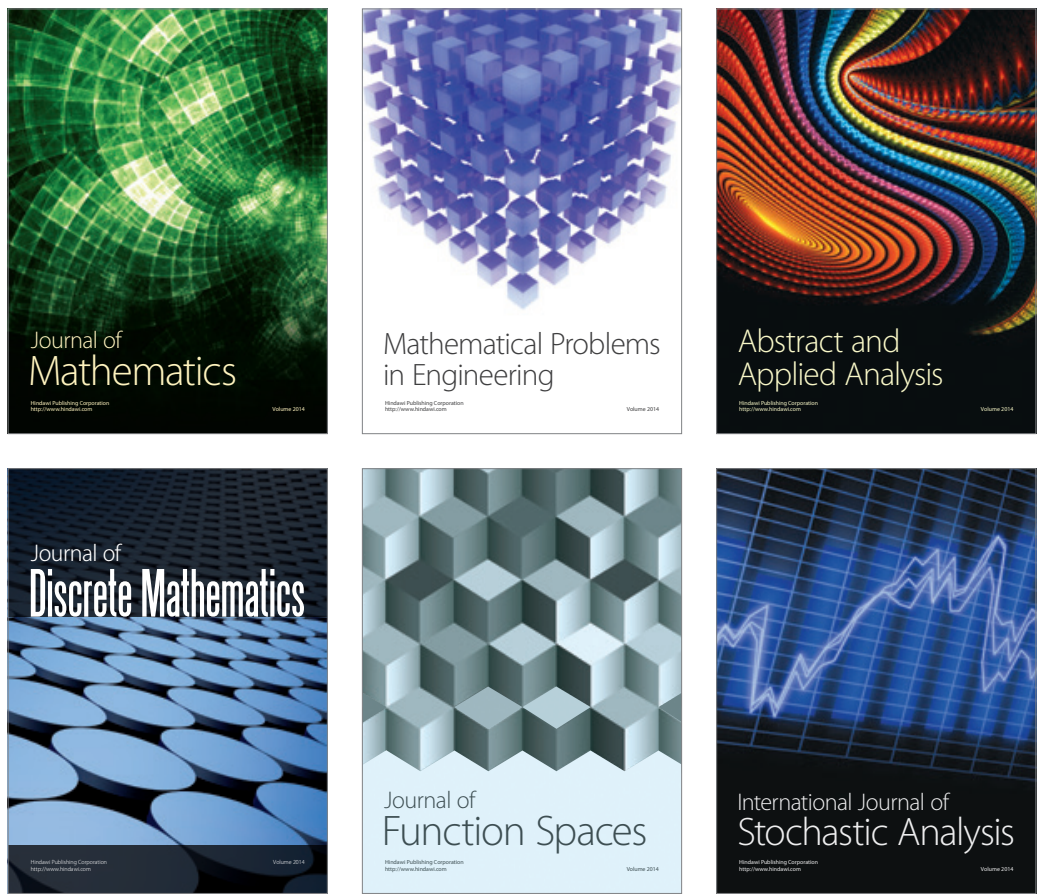

Journal of

Function Spaces

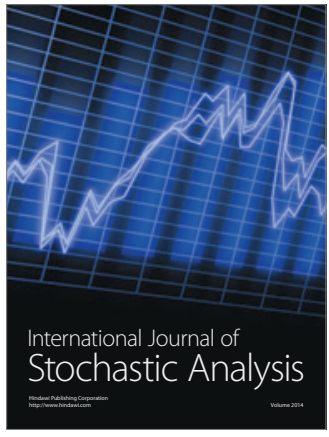

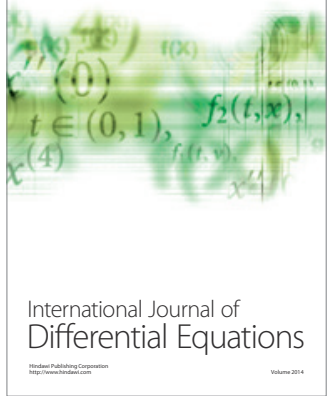
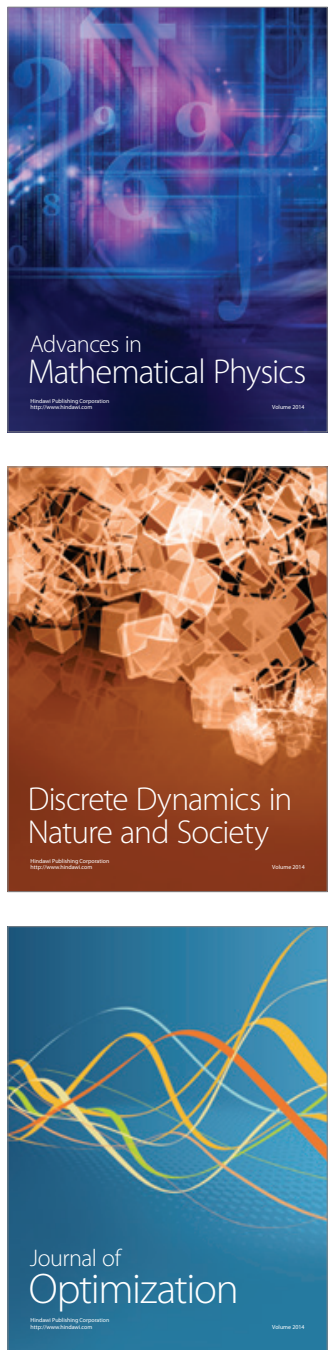